\title{
The Effect of Obesity on Pregnancy in Women
}

\author{
Elif Gelenli Dolanbay (Corresponding author) \\ Istanbul Medeniyet University Faculty of Medicine Department of Histology and Embryology \\ Civilizations Istanbul University North Campus D Block Faculty of Medicine, Department of \\ Histology and Embryology, D-100 highway Side road Unalan Uskudar Istanbul/Turkey 34700 \\ E-mail: egelenli@gmail.com / elif.dolanbay@medeniyet.edu.tr
}

\author{
Melda Yardimoglu Yilmaz \\ Campus of Umuttepe, Kocaeli University Department of Histology and Embryology, Faculty of \\ Medicine, Kocaeli 41380, Turkey \\ Birol Vural \\ Medicana Camlica Hospital Department of Obstetrics and Gynecology Alemdag Street N: 113, \\ 34767 Uskudar/Istanbul
}

\author{
A. Yigit Cakiroglu \\ Acibadem Hospital IVF and Reproductive Health Center, Gynecology and Obstetrics Buyukdere Street \\ N: 4034457 Maslak / Istanbul
}

The research is financed by Kocaeli University Scientific Research Fund (Project no: 2014/11)

\begin{abstract}
Obesity may have negative effects on fertility early onset of obesity in women; menstrual irregularities, chronic oligo-anovulation and infertility in adulthood can be seen. Obesity in women may increase the risk of miscarriage and may adversely affect the outcome of pregnancy achieved with assisted reproductive technologies. The aim of this study is to examine the relationship with the patient groups according to the BMI, pregnancy status and take home baby. 86 female patients which are Normal, owerweight and obes, participated in our study according to Body Mass Index. As the BMIs of the female patients in our study increased, pregnancy rates decreased (N: 43,33\%, FK: 36,67\%, OB 20\%). As the female BMI increased, the rate of babies taking home decreased significantly (N: $81.82 \%$, FK: $9.09 \%$, OB: $9.09 \%$ ). It is understood that obesity has a negative impact on oocyte and embryo quality, pregnancy rates and on baby take home status through hormones and cytokines. We hope that the comprehensive findings obtained in our study showing the effects of only obesity by excluding polycystic ovary syndrome will provide unique and valuable contributions to the literature.
\end{abstract}

Key Words: Obesity, IVF, pregnancy, infertility.

DOI: $10.7176 / \mathrm{JSTR} / 5-4-17$

\section{Kadınlarda Obezitenin Gebeliğe Etkisi}

Özet

Obezitenin doğurganlığa etkisi negatif yönde olabilir Kadınlarda erken dönemde obezitenin ortaya çıkmasıyla birlikte; menstrüyal düzensizlilkler, kronik oligo-anovülasyona ve erişkin yaşta infertilite görülebilir. Kadınlarda obezite düşük riskini arttırabilir ve yardımcı üreme teknolojileri ile elde edilen gebeliğin sonuçlarına olumsuz olarak etki edebilir. Bu çalışmanın amacı Vücut Kitle İndekslerine göre hasta grupları arasında gebelik durumu, eve bebek götürme ile ilişsisinin incelenmesidir. Çalışmamıza katılan 86 kadın hasta; VKI' lerine göre Normal, Fazla Kilolu, Obez olarak sinıflandırıldı. gebelik durumu ile eve bebek götürme oranları kaydedildi. Çalışmamıza katılan kadın hastaların VKI'leri arttıkça, gebelik oranlarında azalma görüldü (N:\%43,33, FK:\%36,67,OB\%20). Kadın VKİ arttıkça, eve bebek 
götürme oranının ciddi oranda azaldığı görüldü (N:\%81,82, FK:\%9,09, OB: :\%9,09). Obezitenin hormonlar ve sitokinler üzerinden oosit ve embriyo kalitesi, gebelik oranları, eve bebek götürme durumu üzerine olumsuz etkileri olduğu anlaşılmaktadır. Polikistik Over Sendromu dışlanarak sadece obezitenin etkilerini gösteren çalışmamızda elde edilen kapsamlı bulguların literatüre özgün ve değerli katkılar sağlayacağını umuyoruz.

Anahtar Kelimeler: Obezite, IVF, gebelik, infertilite.

\section{Giriş}

Obezite, kadınlarda infertilite ile doğurganlığı kendiliğinden yumurtlamayı etkileyerek, yardımlı üreme teknolojisinin (YÜT) etkinliğine ve sonuçlarına kötü etki ederek ve gebeliğin fizyolojik süreçlerini ve doğumu güçleştirerek (Pasquali ve diğ. 2008) etkileyebilir. Kişinin doğurganlık fizyolojisini ceşitli düzeylerde etkileyen bir kapasiteye sahip olan obezitenin doğurganlık işlevleri üzerindeki etkileri yapılan çalışmalar ile açıkça gösterilmiştir. Obezitede üreme ile ilgili hedefler; hipotalamus, over ve folikül, oosit, embriyo ve endometriyumu içermektedir (Tortoriello ve diğ. 2004, Jain ve diğ. 2007, Junkheim ve diğ. 2010, Hirshfeld-Cytron ve diğ. 2011, Woodruff ve Shea 2011, Robker ve diğ. 2009, Yang ve diğg. 2012, Bellver ve diğ. 2011). Obezitenin fertilite üzerindeki olumsuz etkisi; folikülün seçilimi, oosit gelişimi ve kalitesi, oositin fertilizasyonu, embriyo gelişimi ve implantasyonunu da içeren farklı adımlarda olabilmektedir.

\section{Gereç Yöntem}

Çalışmamız için Kocaeli Üniversitesi İnsan Etik Kurulu'ndan KOÜ KAEK 2013/ 80 numaralı Etik Kurul Onayı alındı. Haziran- Kasım 2014 tarihleri arasında Kocaeli Üniversitesi Yardımlı Üreme Teknikleri Merkezi'ne bebek sahibi olmak için gelen kadın hastaların etiyolojisi uygun hastalar çalışmamıza katıldı. Çalışmamıza katılan kadınların tümüne, çalışmamız hakkında ayrıntılı olarak bilgi verildi ve onamları sözlü ve yazılı olarak alındı. Hastaların kilo ve boyları oosit toplama işlemi (OPU) günü ölçülerek, (Vücut ağırlı̆ı̆ $(\mathrm{kg})$ / boy (m2) ) formülüne göre VKİ hesaplandı. DSÖ’ne göre VKİ<25 Normal Kilolu, 25-29 Fazla Kilolu, >30 Obez olarak kabul edildi. Hastaların eşlerinin VKİ değerleri de aynı şekilde hesaplanıp kaydedildi. $\mathrm{N}$ hasta grubu hafif erkek faktör, açıklanamayan infertilite nedeniyle kliniğe başvuran hasta grubundan seçildi. Tüm siklusların klinik ve laboratuvar bilgileri prospektif olarak bilgisayara kaydedildi ve analiz için retrospektif olarak elde edildi. Bütün hastalara pelvik patolojiyi dışlamak ve antral folikül sayısını belirlemek için transvajinal ultrasonografi yapıldı. Hastalara antagonist kontrollü ovaryen hiperstimülasyon uygulandı. Steril bir k1lıf içindeki transvajinal USG probu ve beraberinde tutturulmuş aspirasyon iğnesi overleri görmek ve folikülleri aspire etmek için kullanıldı. Folliküler büyüme düzenli olara kultrason ölçümleri ile takip edildi. En az iki follikül çap $18 \mathrm{~mm}$ olunca $10.000 \mathrm{IU}$ hCG uygulandı. Oosit toplama işlemi hCG yapıldıktan ortalama 36 saat sonra gerçekleştirildi. Oosit toplama öncesi hastalardan idrarlarını yapmaları istendi. Hastalara intravenöz sedasyon uygulandı. Steril bir k1lıf içindeki transvajinal USG probu ve beraberinde tutturulmuş aspirasyon iğnesi overleri görmek ve folikülleri aspire etmek için kullanıldı. Alınan foliküler sıvılar, 16 G'lik iğneler ile $15-20 \mathrm{~mm}$ büyüklügü̈ndeki ve oosit bulunan foliküllere keskin olarak girildikten sonra, $125 \mathrm{mmHg}$ vakum basıncında aspire edilerek elde edildi. Oositlerinin kategorisi belirlenip (MII, MI, Dejenere, EZ oosit); MII ve MI oositlere İntrasitoplazmik Sperm Injection (ICSI) işlemi yapıldı. Embriyoların döllenip döllenmediği 24 saat sonra kontrol edildi. Günlük olarak embriyo gelișimleri takip edildi. Transfer edilen embriyolarda gebelik gerçekleşip gerçekleşmediği kontrol edildi. İstatistiksel değerlendirme, IBM SPSS 20.0 (SPSS Inc., Chicago, IL, USA) paket programı ile yapıldı. Kategorik değişkenler frekans (yüzde) olarak verildi.

\section{Bulgular}

Çalışmamız Haziran-Kasım 2014 tarihleri arasında, toplam 88 hasta üzerinde çalışılmıştır. Hastaların 2 tanesi PKOS (Polikistik Over Sendromu) olması nedeni ile çalışma dışı bırakılmıştır. Çalışmaya katılan hastaların günlük embriyo takipleri yapılıp seçilen iyi embriyoları transfer edildi. Çalışmaya katılan hastaların 31 tanesi Normal Kilolu, 27 tanesi Fazla Kilolu, 30 tanesi Obez olarak gruplandırılmıştır. Çalışmaya katılan 86 kadın hastanın 29 tanesi toplam 86 hastanın \%34,88'i gebe kalmıştır. Gebe kalan hastaların 13 tanesi normal kilolu, 11 tanesi fazla kilolu, 6 tanesi obez grubundadır. Gebe kalan hastaların 11 tanesi evine sağlıklı şekilde bebek götürmüştür. Bu hastaların 9 tanesi normal kilolu, 1 tanesi fazla kilolu, 1 tanesi de obez grubundandır. Çalışmamıza katılan kadın hastaların VKI'leri arttıkça, gebelik oranlarında azalma görüldü Gebelik oranları Normal kilolu kadınlarda N: \%43,33, Fazla kilolu kadınlarda FK: \%36,67, Obezlerde OB: \%9,09 olarak bulunmuştur (Figure:1). Eve bebek 
götürme oran1, normal kilolularda \%81,82 iken, fazla kilolu grupta \%9,09 ve obez grupta \%9,09’a düşmüştür (Figure:2). Kadın VKİ arttıkça, eve bebek götürme oranının ciddi oranda azaldığı görüldü.

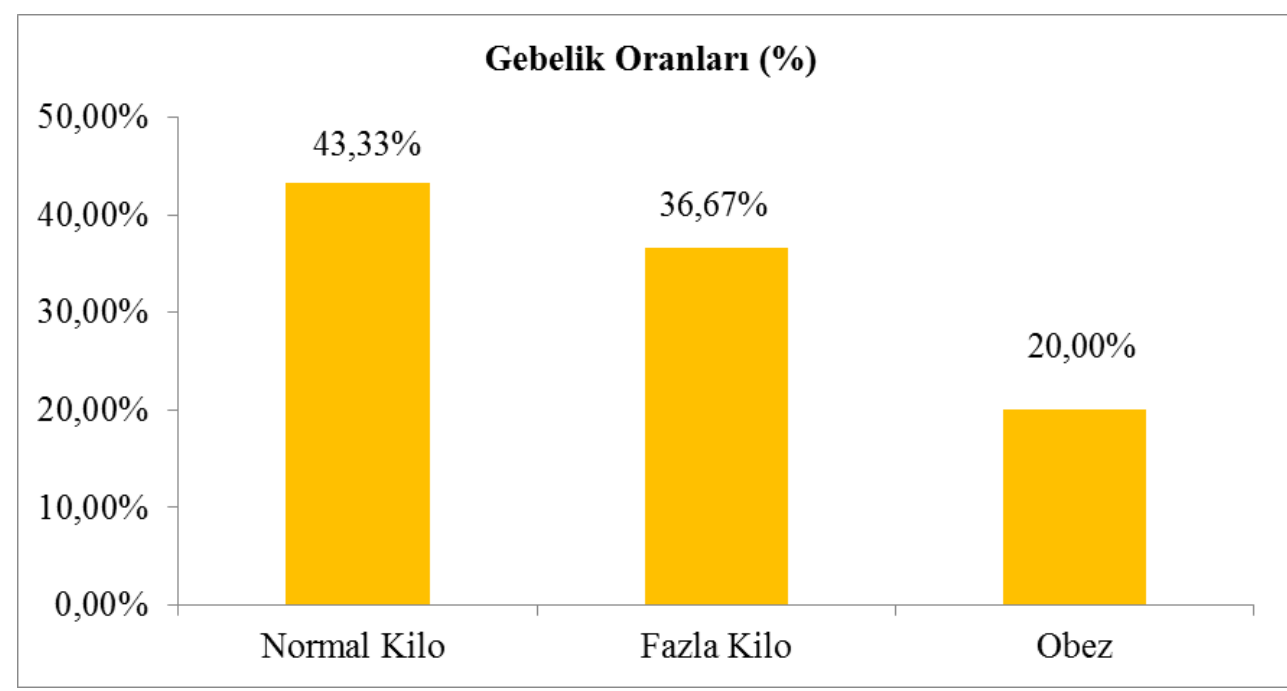

Çalışmaya katılan hastaların gebelik oranları ile kadın (VKİ) arasındaki ilişki.

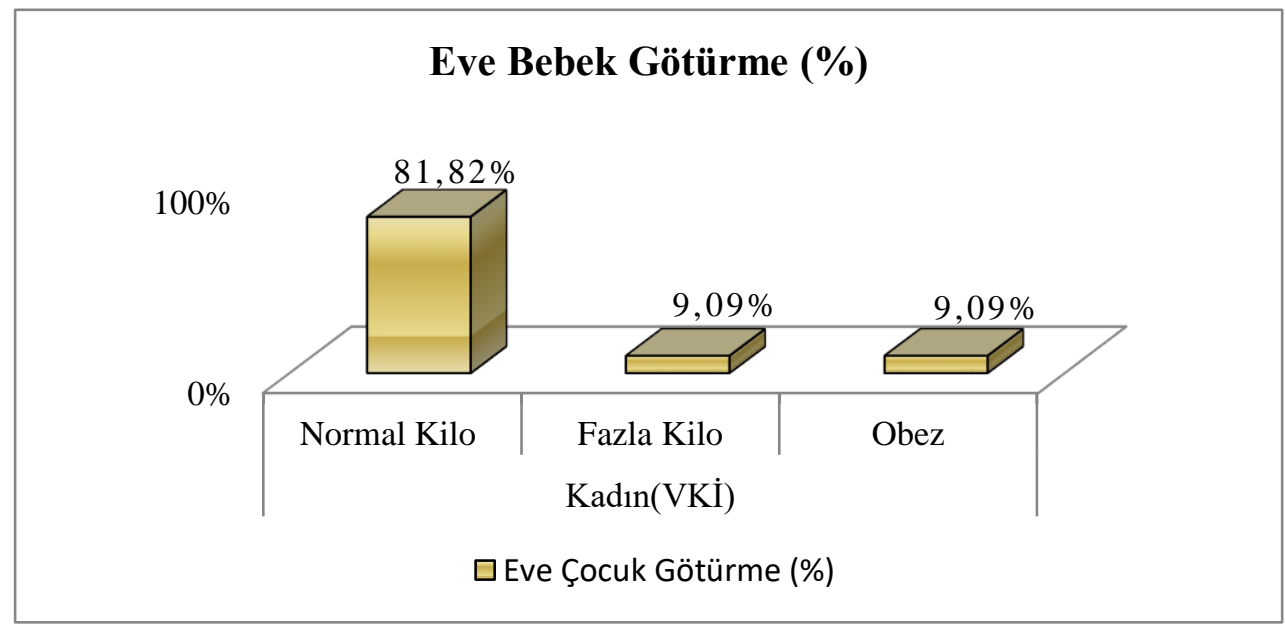

Çalışmamızdaki gebe olan hastaların eve çocuk götürme oranları ile kadın (VKİ) arasındaki ilişki.

\section{Tartışma}

Obezite artık dünyada bir salgındır; toplumun tüm yaş ve sosyal gruplarını, özellikle de kadın cinsiyetini daha çok etkilemektedir. Bu salgın, özellikle kadının yaşam süresini ve kalitesini olumsuz yönde etkilemekle birlikte pek çok organik, sistemik, hormonal, estetik, ruhsal ve toplumsal sorunları da beraberinde getirir (Cordero ve diğ. 2009). Kültür, yeme alışkanlıkları, fiziksel aktivite, sigara ve alkol tüketimi, teknolojik gelişimle birlikte gelen hareketsiz yaşam, hızlı beslenme, yüksek kalorili gıdaların tüketilmesi, milli gelir artışı ve kentleşme, obeziteyi etkileyen genel ruhsal-toplumsal etkenler olup yaş (özellikle ergenlik ve premenopozal dönem) evlilik, gebelik, doğum sayısı, emzirme süresi, gibi etkenler de kadına özgü obezite nedenleri arasında sayılabilir. Kadınlar biyolojik faktörlerin etkisi ile ergenlik döneminin başından itibaren erkeklere oranla daha kiloludurlar. Ergenlik, gebelik, doğum sayısı, emzirme süresi, menopozal dönem ve emeklilik gibi yaşam dönemleri kadın için önemli riskli dönemler olarak kabul edilmektedir (Belahsan ve Rguibi 2006, Gavin ve diğ 2010, Cordero ve diğ. 2009, Haslam 2005). Adölesan dönemin başlangıcında kadınlarda ayrıca fizyolojik olarak, östrojen hormonunun etkisi ile vücut yağ dokusu, kas kütlesine oranla artar ve menopoz, gebelik gibi durumlar ağırlık artışına pozitif etki eder. Menopoza geçişin vücut yağ dağılımı üzerine etkisi açık olmamakla 
birlikte bazı çalışmalar merkezi ve yağ birikiminin özellikle karın içi yağların menopoza geçiş ile ilişkili olduğunu göstermektedir (Kanter ve Caballero 2012, Cordero ve diğ. 2009, Haslam 2005, Odom 2006).Obezite prevelansının dünya çapında endişe verici artışı, DSÖ'nün obeziteyi 21.yüzyılın en ciddi küresel sağlık sorunlarından biri olarak dikkate almasına yol açmıştır. DSÖ şişmanlık ve obeziteyi "sağlığa zarar veren anormal ya da aşırı yağ birikimi" olarak tanımlamıştır (Sirimi ve Goulis 2010, Lee ve Koren 2010). Ovulasyon indüksiyonu ya da YÜT sonrasında obezlerin gebelik oranlarının daha düşük olup olmadığı halen tartışmalıdır (Bellver ve diğ. 2006). Bir diğer çalışmada; YÜT tedavisi esnasında en az bir gebelik elde edilme olasılığının VKI'si 30-35 kg/m2 olan kadınlarda yaklaşık olarak \%30; VKI'si $35 \mathrm{~kg} / \mathrm{m} 2$ 'den fazla olan kadınlarda $\% 50$ oranında azaldığını göstermişlerdir (Wang ve diğ. 2000). Bizim çalışmamızda gebelik oranları; normal kilolu hasta grubunda $\% 43.33$, fazla kilolu hasta grubunda $\% 36,67$, obez hasta grubunda $\% 20$ olarak bulunmuştur. Bu sonuca göre bizim çalışmamızda kadın (VKI) arttıkça gebelik oranları azalmıştır. Obez kadınların IVF sonrası klinik olarak hamile kalma şansı normal kilolu kadınlara nazaran daha düşük (Jungheim ve diğ. 2009), YÜT sonrası düşük yapma ihtimali daha yüksek, (Rittenberg ve diğ. 2011, Rittenberg ve diğ. 2011) ve IVF sonrası canlı doğum şansı daha düşük olduğunu bildiren çalışmalar da mevcuttur (Jungheim ve diğ. 2010). Bizim çalışmamız bu sonuçları destekler eve bebek götürme oranları normal kilolu hasta grubunda $\% 81,82$; fazla kilolu hasta grubunda $\% 9,09$, obez hasta grubunda ise $\% 9,09$ olarak bulunmuş olup; kadın VKİ arttıkça eve bebek götürme oranının dramatik olarak azaldığı görülmüştür.

\section{Sonuç}

Çalışmamıza katılan kadın hastaların VKI'si arttıkça gebelik oranlarında azalma görüldü. Bu, obezitenin fetiliteye negatif etkilerinin olduğuna katkı sağlayan bir bulgudur. Obezitenin doğurganlık fonksiyonları üzerindeki etkileri üzerinde yapılan çalı̧̧malarda obezitenin kişinin doğurganlık fizyolojisini farklı farklı düzeylerde etkileyen önemli bir etken olarak karşımıza çıkmaktadır. Obezite hipotalamus, over ve folikül, oosit, embriyo ve uterin endometriyuma olan etkiletiyle üremeyi etkiler. Folikülün seçilimi, oosit gelişimi ve kalitesi, oositin fertilizasyonu, embriyo gelişimi ve implantasyonunu da içeren farklı aşamalarda obezite fertiliteyi olumsuz olarak etkileyebilir. Obezite ile eşlik eden hormon değişiklikleri, korpus luteum ile trofoblast işlevini, erken embriyo gelişimini ve endometriyumun reseptivitesini etkileyebilir. Halen tartışmalı da olsa implantasyon da obeziteden negatif şekilde etkilenmektedir. Obezitenin hormonlar ve sitokinler üzerinden; oosit ve embriyo kalitesi, gebelik oranları, eve çocuk götürme durumu üzerine olumsuz etkileri olduğu anlaşılmaktadır. Obez kadınların normal kilolu kadınlara kıyasla IVF sonrası klinik olarak hamile kalma şansı daha düşük, YÜT sonrası düşük yapma ihtimali daha yüksek, ve IVF sonrası canlı doğum şansı daha düşük olduğunu bildiren çalışmalar da mevcuttur. Bizim çalışmamız da bu bulguları desteleyerek eve bebek götürme oranının, kadın VKİ arttıkça ciddi oranda azaldığ 1 saptandı. PKOS dışlanarak sadece obezitenin etkilerini gösteren çalışmamızda elde edilen bulguların literatüre özgün ve değerli katkılar sağlayacağını umuyoruz.

\section{References}

Belahsan R, Rguibi M. (2006). "Population Health and Mediterranean Diet in Southern Mediterranean Countries. Public Health Nutrition,” Dec, 9(8A),s.1130-1135

Bellver J, Busso C, Pellicer A, et al. (2006). "Obesity and assisted reproductive technology outcomes.” Reprod Biomed Online, 12,s.562-568.

Bellver J, Martinez-Conejero JA, Labarta E, Alama P, Melo MA, Remohi J, et al.(2011). “ Endometrial gene expression in the window of implantation is altered in obese women especially in association with polycystic ovary syndrome." Fertil Steril,95,s.2335-41.

Cordero A et al. (2009). Casasnovas on behalf of the MESYAS Registry investigators. Gender differences in obesity related cardiovascular risk factors in Spain. Preventive Medicine , 48:134139. doi.10.1016/j.ypmed.2008.10.024.

Gavin A, Simon GE, Ludman E. The association between obesity, depression, and educational attainment in women: The mediating role of body image dissatisfaction.(2010) Journal of Psychosomatic Research; 69 (6): 573-581. Do10.1016/j.jpsychores.2010.05.001. 
J.E. Hirshfeld-Cytron, F.E. Duncan, M.Xu, J.K. Jozefik,L.D. Shea, and T.K.Woodruff, (2011), Animal age, weight and estrus cyclestage impact the quality of in vitro grown follicles Journal of Human Reproduction. June 13, 2011 26, 9 2473-2485, doi:10.1093/humrep/der183

Haslam D. Gender-specific aspects of obesity. Journal of mens Health and Gender, 2005 WPMH $\mathrm{GmbH}$. Published by Elsevier Ireland Ltd. 2005 June; 179: (2): 179-185. doi:10.1016/j. jmhg.2005.04.015.

Jain A, Polotsky AJ, Rochester D, Berga SL, Loucks T, Zeitlian G, et al. (2007).’Pulsatile luteinizing hormone amplitude and progesterone metabolite excretion are reduced in obese women. J Clin Endocrinol Metab ,92, s.2468-73. [CrossRef].

Jungheim ES, Lanzendorf SE, Odem RR, Moley KH, Chang AS, Ratts VS. (2009). "Morbid obesity is associated with lower clinical pregnancy rates after in vitro fertilization in women with polycystic ovary syndrome. Fertil Steril, 92, s.256-61.

Jungheim ES, Schoeller EL, Marquard KL, Louden ED, Schaffer JE, Moley KH. (2010). “ Dietinduced obesity model: abnormal oocytes and persistent growth abnormalities in the offspring. Endocrinology.", 151,s. 4039-46.

Kanter R, Caballero B.(2012)." Global Gender Disparities in Obesity. "A Review. Advances in Nutrition An International Review Journal , 3, s.491-498.

Lee CY, Koren G. (2010).’Maternal obesity: effects on pregnancy and the role of pre-conception counselling." J Obstet Gynaecol. ,30(2),s.101-106.

Odom N.J. (2006). "Overweight and Obesity in Women: A Literature Review. The University of Arizona. A Master's Project Submitted to the Faculty of the Arizona. College of Nursing ." Master of Science in Nursing, 2,s.72.

Pasquali R, Laura Patton ve Alessandra Gambineri Obezite ve infertilite Current Opinion in Endocrinology, Diabetes \& ObesityTÜRKÇE BASKI Cilt 3, Sayı 1, 2008.

Rittenberg V, Sobaleva S, Ahmad A, Oteng-Ntim E, Bolton V, Khalaf Y, et al. Influence of BMI on risk of miscarriage after single blastocyst transfer. Hum Reprod 2011; 26: 2642-50.

Rittenberg V, Seshadri S, Sunkara SK, Sobaleva S, Oteng-Ntim E, El-Toukhy T. Effect of body mass index on IVF treatment outcome: an updated systematic review and meta-analysis. Reprod Biomed Online 2011; 23: 421-39.

Robker RL, Akison LK, Bennett BD, Thrupp PN, Chura LR, Russell DL, et al. (2009).”Obese women exhibit differences in ovarian metabolites, hormones, and gene expression compared with moderateweight women." J Clin Endocrinol Metab, 94, s.1533-40.

Sirimi N, Goulis DG.(2010).” Obesity in pregnancy. Hormones “, 9(4),s. 299-306.

Tortoriello DV, McMinn J, Chua SC. (2004)Dietaryinduced obesity and hypothalamic infertility in female DBA/2J mice. Endocrinology; 145: 1238-47 [CrossRef].

Wang J, Davies M, Norman R. (2000);Body mass and probability of pregnancy during assisted reproduction treatment: retrospective study. Br Med J 321:1320-1321.

Woodruff TK, Shea LD.(2011).” A new hypothesis regarding ovarian follicle development: ovarian rigidity as a regulator of selection and health." J Assist Reprod Genet, 28, s.3-6.

Yang X, Wu LL, Chura LR, Liang X, Lane M, Norman RJ, et al.(2012).” Exposure to lipidrich follicular fluid is associated with endoplasmic reticulum stress and impaired oocyte maturation in cumulus oocyte complexes." Fertil Steril, 97, s.1438-43. 